\title{
Governmental Spending on Public Cultural Services: Efficiency and Influencing Factors Analysis Based on DEA-Tobit
}

\author{
Bin Tu1 ${ }^{*}$, Xiangyu Tao², Nian'en Guo ${ }^{2}$ \\ ${ }^{1}$ Guangdong Research Center for NPO, Guangdong University of Foreign Studies, Guangzhou, China \\ ${ }^{2}$ School of Politics and Public Administration, Guangdong University of Foreign Studies, Guangzhou, China \\ Email: *hattytu@126.com
}

How to cite this paper: Tu, B., Tao, X.Y. and Guo, N.E. (2017) Governmental Spending on Public Cultural Services: Efficiency and Influencing Factors Analysis Based on DEA-Tobit. Journal of Service Science and Management, 10, 216-229.

https://doi.org/10.4236/jssm.2017.103019

Received: April 25, 2017

Accepted: May 24, 2017

Published: May 27, 2017

Copyright $\odot 2017$ by authors and Scientific Research Publishing Inc. This work is licensed under the Creative Commons Attribution International License (CC BY 4.0).

http://creativecommons.org/licenses/by/4.0/

\begin{abstract}
Based on the panel data of provinces in China from 2000 to 2015, this article explores the efficiency of local government spending on public cultural services and its influencing factors under the DEA-Tobit two-stage analysis framework. First, the comprehensive efficiency, pure technical efficiency and scale technical efficiency of local government public cultural expenditure were measured through the data envelopment analysis method (DEA). On the basis of the first step analysis, we use Tobit model with the limited dependent variable to study the relationship between the efficiency evaluation results and policy variable such as fiscal decentralization, cultural policy, the relationship between the efficiency evaluation results and social factors like per capita GDP, population density and residents' educational level etc. Through the analysis of the evaluation results, it is found that there were significant differences in the local efficiency on public cultural expenditure in China. The effects of population density, urbanization level, per capita GDP and illiteracy rate on the efficiency of government public cultural expenditure are positive. After controlling population, economic and social factors, the effect of fiscal decentralization on the efficiency of public cultural expenditure is negative, and cultural policy has significantly promoted the efficiency of Chinese local government cultural expenditure.
\end{abstract}

\section{Keywords}

Government Cultural Spending, DEA-Tobit, Fiscal Decentralization, Cultural Policy

\section{Introduction}

It's very important for government to improve deliveries of public cultural ser- 
vices to meet the citizens' basic cultural needs in China. Public cultural services, provided mainly by government due to the slow development of cultural nonprofit organizations, include public cultural facilities (such as library, museum, memorial, art museum and cultural center etc.), cultural products, cultural activities and other related cultural services. The essence of public cultural services is, in the citizen, to form identity on positive value orientation and noble spiritual pursuit which can shape people's good behavior, and maintain social stability at the end. All of these functions are predicated on government spending sustainability and require a high spending efficiency strong and understanding of the factors that affect spending efficiency. This article contributes to the knowledge by exploring the determinants of efficiency on government cultural spending.

Research indicates that in the allocation of funds for public cultural expenditure which is government spending on the public cultural services, the cultural authorities often spend most of the funds on the wages of employees in public cultural institutions. There is a serious shortage of funds for the development of public culture (M. Han, 2009) [1], as a result, the overall efficiency of the use of financial funds is not high, so the way of input on cultural financial funds needs to be further optimized (G. He, 2009) [2]. The proportion of fixed investment should be gradually reduced and the proportion of dynamic input in public cultural services should be increased. In order to improve the efficiency on the use of cultural financial subsidies the funds general input should gradually turn to project-oriented from cultural institutions-oriented, the government procurement system need to be gradually established and improved. The bidding system and intermediary evaluation system should be especially implemented for national cultural activities with special requirements and supports, cultural facilities and research projects (P. Wei, 2005) [3].

There is a coexistence between the absence and the offside in the input project on public cultural services. The public cultural services provided by government and depending on government financial resources need to meet the basic cultural needs of the citizen. However, "ahead of consumption" phenomenon of public culture is very serious in some region, a large amount of funds is used for the construction of the cultural "enjoyment consumption" facilities, the financial expenditures haven't tilted to the public's basic cultural needs. There is a lack of enough comprehensive management and monitoring on cultural projects and project evaluation mechanism. The average allocation of project funds is an obvious trend, the inefficient on the use of cultural project funds (Ma Haitao, Cheng Lan, 2009) [4]. Thus, in the government cultural project selection, the project with a larger demand for the public should be selected as a priority choice. Inputs on connected radio and television project, township comprehensive cultural station and grassroots cultural construction, rural film screening, farm house construction etc. should be increased in the rural areas. Inputs on the library, museum and cultural hall should be mainly increased in the city, in order to strengthen community culture (Jiang Guanghua, 2011) [5]. 
Despite this recognition, researchers in China predominantly describe the phenomenon in government cultural spending, and lack of in-depth analysis. The idea that efficiency on government cultural spending was not enough has been discussed, but rarely mentions the evaluation on efficiency and the influencing factor on the efficiency. What's the efficiency on public cultural services spending of the different local government? What factor will affect the government cultural spending efficiency? As a result, we do not have a clear understanding of the efficiency and its effects of efficiency. This paper explores the efficiency on the government spending on public cultural services and its effects of efficiency and influencing factor of its efficiency. The paper consists of four parts. We introduce the research topic and present a literature review at first. Next we evaluate the public cultural expenditure efficiency on 30 provinces. Afterwards, we analyze the influencing factor on efficiency of public cultural expenditure. Finally, we get conclusions and provide suggestions on how to improve efficiency of government spending on public cultural services.

\section{Public Cultural Expenditure Efficiency Evaluation}

\subsection{DEA Method and Data}

The DEA method is a nonparametric statistical method used to evaluate a multiinput, multi-output decision-making unit with the same type is technically effective or not. The principle is mainly to determine the relatively effective production frontier through keeping the Decision Making Units (DMU) input or output unchanging, using mathematical programming and statistical data. The DMU was projected to DEA production frontier, and the relative effectiveness of the decision making unit is evaluated by the degree of deviation from the DEA frontier. In order to set forth the changing condition of returns to scale where increasing the output with unequal proportion by increasing the input, this paper adopts the BCC model. The research purpose of the paper is the public cultural expenditure efficiency of local government, thus we chose 30 provinces from 31 provinces in China as 30 decision-making units, it's difficult to obtain complete data of the rest province, Tibet. It has been removed from the decisionmaking units. The data of cultural expenditure before 2000 is scattered, so the time from 2000 to 2015 is selected as Research period.

\subsection{Selection of Variables}

The selection of variables indexes is shown in Table 1 . The input variable is the public cultural expenditure, which adopts the annual public cultural expense in 30 provinces. The output variables contain the cultural resources, which can directly provide public cultural products (number of cultural institutional organizations, new purchased copies of books in public libraries, average times of performance per art performance troupe of the cultural sector, practical completed investment in capital construction by cultural undertakings). Relevant data comes from the China Statistical Yearbook, China Statistical Yearbook of Cul- 
Table 1. DEA-TOBIT analysis of correlated variables for public cultural expenditures efficiency.

\begin{tabular}{|c|c|c|}
\hline Input Variables & Output Variables & Factors Affecting Efficiency \\
\hline \multirow{6}{*}{$\begin{array}{l}\text { Provincial } \\
\text { Cultural } \\
\text { Expenditures } \\
\text { in Each Year }\end{array}$} & The number of Cultural Institutions & $\begin{array}{l}\text { Density of Population } \\
\text { (per/square kilometer) }\end{array}$ \\
\hline & $\begin{array}{l}\text { Employed Population in Public Culture } \\
\text { (The sum of Employed Population in } \\
\text { Public Cultural Institutions) }\end{array}$ & Per Capital GDP \\
\hline & $\begin{array}{c}\text { Actual Number of Completed } \\
\text { Cultural Infrastructure Investment }\end{array}$ & $\begin{array}{c}\text { Urbanization Level (Urban } \\
\text { Population/Total Population) }\end{array}$ \\
\hline & $\begin{array}{l}\text { Recent Acquisitions } \\
\text { to the Public Libraries }\end{array}$ & Educational Level \\
\hline & $\begin{array}{l}\text { Average Performance Number of } \\
\text { Theatrical Troupes of Cultural Institutions }\end{array}$ & Fiscal Decentralization \\
\hline & $\begin{array}{l}\text { Total Number of Visitors } \\
\text { of Public Libraries }\end{array}$ & $\begin{array}{c}\text { Change of Cultural } \\
\text { Policy after } 2006\end{array}$ \\
\hline
\end{tabular}

tural Heritage, China Finance Yearbook and China Population Statistical Yearbook.

\subsection{Efficiency Evaluation}

Based on the output-oriented DEA model, DEAP 2.1 is used to obtain the evaluation results of the public cultural expenditure efficiency of the provincial governments (Table 2). Next, the evaluation results of the overall technical efficiency, pure technical efficiency and scale technical efficiency of the public cultural expenditures are analyzed in horizontal and longitudinal time sequences.

\section{Result and Discussion}

From the perspective of horizontal regional differences, significant difference was found in the overall technical efficiency of public cultural expenditures between the provinces. The overall technical efficiency is a measure of the total efficiency of the decision-making units. The overall technical efficiency of seven provinces is 1 and both the technical efficiency and scale efficiency are achieved, which indicates that the DEA of these seven provinces is effective and the provinces constitute the frontier of the domestic public cultural expenditure efficiency. Theoretically, compare with other regions, the resource allocation of the public cultural expenditures of these seven provinces reaches the optimal outcome, and the efficiency is relatively high. Four of these seven provinces are located in the west, and the rest belong to the eastern part. Among the top ten provinces in overall technical efficiency, six provinces belong to the western part, while three provinces are located in the east. There are five provinces with overall technical efficiency of less than 0.6, among which Liaoning, Jilin, and Fujian have relatively low overall technical efficiency. Most of the central provinces are in the rank of provinces with relatively low public cultural expenditure efficiency, thus it can be seen that, the public cultural expenditures of the majority of 
Table 2. Evaluation result of public cultural expenditures efficiency.

\begin{tabular}{|c|c|c|c|c|}
\hline Province & crste & vrste & scale & rte \\
\hline Beijing ${ }^{1}$ & 0.752 & 0.819 & 0.941 & drs \\
\hline Tianjin $^{1}$ & 0.751 & 1 & 0.751 & drs \\
\hline Hebei & 1 & 1 & 1 & - \\
\hline Shanxi & 0.825 & 0.833 & 0.991 & irs \\
\hline Neimenggu & 0.672 & 0.681 & 0.977 & irs \\
\hline Liaoning & 0.514 & 0.562 & 0.896 & drs \\
\hline Jilin & 0.507 & 0.523 & 0.966 & irs \\
\hline Heilongjiang & 0.785 & 0.794 & 0.995 & irs \\
\hline Shanghai ${ }^{1}$ & 0.657 & 1 & 0.656 & drs \\
\hline Jiangsu & 0.623 & 0.645 & 0.961 & drs \\
\hline Zhejiang & 1 & 1 & 1 & - \\
\hline Anhui & 0.582 & 0.611 & 0.96 & irs \\
\hline Fujian & 0.511 & 0.526 & 0.979 & irs \\
\hline Jiangxi & 0.824 & 0.842 & 0.981 & irs \\
\hline Shandong & 0.618 & 0.637 & 0.967 & drs \\
\hline Henan & 0.716 & 0.74 & 0.978 & drs \\
\hline Hubei & 0.603 & 0.604 & 0.996 & irs \\
\hline Hunan & 0.625 & 0.627 & 0.998 & irs \\
\hline Guangdong & 1 & 1 & 1 & - \\
\hline Guangxi & 0.633 & 0.652 & 0.976 & irs \\
\hline Hainan & 0.675 & 0.948 & 0.712 & irs \\
\hline Chongqing $^{1}$ & 1 & 1 & 1 & - \\
\hline Sichuan & 0.667 & 0.896 & 0.746 & drs \\
\hline Guizhou & 0.838 & 0.886 & 0.955 & irs \\
\hline Yunnan & 0.573 & 0.575 & 0.993 & irs \\
\hline Shanxi & 0.898 & 0.941 & 0.952 & irs \\
\hline Gansu & 1 & 1 & 1 & - \\
\hline Qinghai & 1 & 1 & 1 & - \\
\hline Ningxia & 1 & 1 & 1 & - \\
\hline Xinjiang & 0.665 & 0.704 & 0.945 & irs \\
\hline
\end{tabular}

Notes: crste: overall technical efficiency, vrste: pure technical efficiency, scale: scale technical efficiency, rte: scale returns (drs: diminishing returns to scale, -: scale remuneration unchanged, irs: Increased scale returns, crste $=$ vrste $\times$ scale.

provinces in our country are non-DEA effective. The average public cultural expenditure efficiency is relatively high in the western provinces, relatively low in the central provinces, while not high in the eastern provinces (below 0.7 in most 
cases). The average value is 0.736 for the eastern provinces, 0.685 for the central provinces and 0.816 for the western provinces, and the difference is significant.

For non-DEA effective public cultural expenditure efficiency, we can analyze it from aspects of technical efficiency and scale efficiency, respectively. The overall technical efficiency is obtained by product of pure technical efficiency and scale technical efficiency, that's to say, the non-DEA effectiveness of overall technical efficiency can be divided into pure technical efficiency and scale technical efficiency for further analysis of the reason. So pure technical efficiency and scale technical efficiency can be used to measure the low efficiency of public cultural expenditures, that is, to what extent the low efficiency is caused by the pure technical inefficiency or the scale technical inefficiency. On the premise of fixed public cultural expenditure scale, pure technical efficiency reflects the level of budget management and the reasonable degree of cultural regional planning of local government. Under the condition of fixed input, scale technical efficiency is the ratio of the output of the production frontier to the output in the optimal scale. The larger the scale efficiency, the closer the production scale of the decision-making unit to the optimal production scale. In addition, by changing the constraint conditions, the type of returns to scale of the decision-making unit can be judged by the DEA model of the alterable returns to scale. If increasing returns to scale appears, it's indicated that the decisionmaking unit can improve the production efficiency by expanding the production scale; if decreasing returns to scale appears, the input structure needs to be adjusted to improve the production efficiency.

It can be concluded from the Table 2 that the pure technical efficiency of Tianjin and Shanghai is effective but the scale technical efficiency is low, indicating that the non-DEA effectiveness of these two provinces is mainly caused by the low scale technical efficiency. The public cultural expenditures exceed the optimal scale, so the scale efficiency should be improved under the condition of maintaining reasonable current budget management level and cultural regional planning; Hubei and some other provinces have a relatively high score of scale efficiency, which is close to the effective scale efficiency but belongs to noneffectiveness of pure technical efficiency, indicating that the low overall efficiency of these provinces is mainly induced by the pure technical efficiency, so we should focus on improving the budget management level as well as the cultural regional planning level. In particular, the score of scale efficiency of Yunnan is 0.993 , while the score of pure technical efficiency is 0.573 , so we should pay even more attention to improve the level of budget management and cultural regional planning. However, more of the local public cultural expenditures are neither pure technical effective nor scale effective. Liaoning has the lowest overall technical efficiency, which is mainly caused by its pure technical efficiency. For most of the central provinces, the reason of their relatively low overall technical efficiency mainly lies in the low pure technical efficiency and the loss of scale efficiency, and the pure technical inefficiency is the main influencing factor (see Table 3). Moreover, from the perspective of returns to scale, most of the public 
Table 3. Returns to scale of provincial public cultural expenditures.

\begin{tabular}{cccc}
\hline Increased scale returns (irs) & $\begin{array}{c}\text { scale remuneration } \\
\text { unchanged (-) }\end{array}$ & $\begin{array}{c}\text { diminishing returns } \\
\text { scale(drs) }\end{array}$ \\
\hline Shanxi, Neimenggu, Jilin, & Hebei, Zhejiang & Beijing, Liaoning, \\
Provingxe & Guangdong, & Jiangsu, Shandong, \\
Fujian, Hubei, Hunan, & Tianjin, Shanghai, \\
Hainan, Chongqing, Yunnan, & Guizhou, Gansu, & Qinghai, Ningxia & Henan, Guangxi, \\
Shanxi, Xinjiang & & Sichuan \\
\hline
\end{tabular}

cultural expenditures of local government are at the stage of increasing returns to scale, that's to say, if these local public cultural expenditures increase the number of all input resources in the same proportion, a greater proportion of returns will be achieved. However, for local government with decreasing returns to scale, it may not be the best choice to blindly pursue the increase of the scale of public cultural expenditures.

It can be seen from the longitudinal perspective that over an sixteen-year period, the average overall technical efficiency of China's public cultural expenditures was basically within a range of 0.5 to 0.6 before 2007, the fluctuating margin of the changes was relatively large, and the efficiency has been in a rising trend since 2007; both the pure technical efficiency and scale technical efficiency were in fluctuation within a narrow range before 2007. In later years, although they decreased in some individual years, the overall change was increasing. On the whole, the average overall technical efficiency, the average pure technical efficiency and scale technical efficiency of public cultural expenditures of the provinces in China are all in a rising trend.

\section{Influencing Factor on Efficiency Analysis}

\subsection{The Basic Hypothesis}

For the uncontrollable factors affecting the public cultural expenditure efficiency of local government, after summarizing the influencing factors in previous literature, the paper selected the population density, Per Capita GDP, and urbanization level and illiteracy rate as factors affecting the efficiency of population, economy and society, respectively. In addition, the paper also investigated the influence of fiscal decentralization and cultural policies after 2006 on public cultural expenditure efficiency of local government (see Table 1). It can be seen that, from the above analysis in the second part, obvious difference exists in the public cultural expenditure efficiency of the eastern, central and western regions (the dummy variables of the eastern, central and western regions will be introduced for further demonstration ${ }^{2}$ ). Concluding from previous researchers' research results, the paper makes the following assumptions on the potential factors that affect the efficiency variance of local public cultural expenditures:

Hypothesis 1 (H1): Public culture positively related to the level of GDP per

\footnotetext{
${ }^{2}$ The western region are taken as the reference region and the intercept coefficient of the constant term in the model as the average expenditure efficiency level of the western region to test the statistical significance of the efficiency variances between the three regions.
} 
capita expenditure. Since the public expenditure of cultural services has relatively larger income elasticity of service needs compared to other public expenditures, namely, with the rise in real income per capita, the needs for these services has also increased, resulting in the growth trend of public cultural expenditures. Netzer (1992) [6] found that GDP (income) or income related variables (such as the higher receipts tax accompanied by the higher public expenditures) are major determinants of public cultural expenditure, while other explanatory variables including the institutional factor merely show weak positive correlation with the public cultural expenditure.

Hypothesis $2(\mathrm{H} 2)$ : The higher the level of urbanization, the stronger the radiation function of urban communal facilities on rural areas, that is, the urbanization rate has a positive impact on the public cultural expenditure efficiency. W. Lin (2005) [7] found that the level of urbanization has significant influence on the integrating supply of urban and rural public goods, thus affecting the expenditure efficiency. N. Zhang (2006) [8] selected the urbanization rate as an indicator which affects the efficiency of rural fiscal expenditure.

Hypothesis 3 (H3): The population density is positively related to the public cultural expenditure efficiency. It's considered that the population density should be positively correlated to efficiency of the government expenditures (Grossman, 1999) [9]. Due to the influence of scale economy, higher population density is conductive to reduce the cost of management and supervision of government expenditures, and providing public services to the increasing size of residents will bring out scale economy, thus resulting in increase of the expenditure efficiency. Besides, Athanassopoulos (2003) [10] found that the population density and the total population have negative influence on the governmental efficiency.

Hypothesis 4 (H4): The educational level is positively related to the public cultural expenditure. Residents with higher educational level have higher cultural needs for themselves, and they can better express their needs through various channels, accordingly, the government is given the stress to increase the public expenditure in this field. Therefore, the higher educational level of residents is conducive to improve the local government expenditure efficiency (Milligan, 2004) [11]. Here, the educational level is expressed by the illiteracy rate (refers to ratio of population aged 15 and over, who are unable or very difficult to read) (H. Han, Y. Miao, 2010) [12].

Hypothesis 5 (H5): Fiscal decentralization is related to the public cultural expenditure. Fiscal decentralization is a basic fiscal system arrangement after the tax sharing reform in China. Fiscal decentralization may exert an influence on the scale, structure and efficiency of local fiscal expenditure. The mainstream theory of fiscal decentralization in western countries argues that the competition between different local governments will stimulate the local governments to constantly take measures on their initiative to improve the efficiency of public goods supply, thus contributing to the rise in the social general welfare level. The share of fiscal expenditure per capita in the total fiscal expenditure per capita of 
a province is taken as a measure of fiscal decentralization ${ }^{3}$. Meanwhile, in order to investigate the different impacts of fiscal policies on three regions, i.e., the eastern, western and central China, the interaction item of fiscal decentralization variables and three regional dummy variables is introduced.

Hypothesis 6 (H6): Cultural policy is an important factor affecting the cultural expenditure efficiency. The issuing of The State Eleventh Five-Year plan for construction of culture marked the emergence of a medium and long-term planning strategy, which is the first state-level strategy after the reform and opening up, and it has its authority and is specialized in the deployment of cultural construction in 2006. Since then, the situation in which the power of formulating cultural policies was highly concentrated in the central government during the period of planned economy was changed, and localization of cultural policies appeared, which was more suitable for the development of the cultural field. Here, we introduced the annual virtual variable to represent the change of cultural policies during this period. In consideration of the hysteresis quality of the policies, it's stipulated that the virtual variable is assigned 1 after 2007 and 0 in other years. At the same time, in order to investigate the different influence of cultural policies on the three regions of the east, the west and the central region, the interactive term of the dummy variable of the cultural policies and the dummy variable of the three regions is introduced. Based on the cultural development and change course, the paper argues that system is an important factor affecting the cultural expenditure efficiency. Therefore, we'll emphatically investigate the influence of two policy variables in the model, i.e., fiscal decentralization and cultural strategic change, on the expenditure efficiency of cultural undertakings of the government.

\subsection{Model and Empirical Result}

Based on the above assumptions, the following regression model can be obtained:

$$
z_{i t}=\beta_{i 0}+\beta_{i 1} \chi_{i 1}+\beta_{i 2} \chi_{i 2}+\beta_{i 3} \chi_{i 3}+\beta_{i 4} \chi_{i 4}+\beta_{i 5} D_{i j}+\varepsilon_{i t}
$$

$z_{i t}$ represents the evaluation result of overall technical efficiency of provinces in China during year 2000 to 2014, $\chi_{i 1}, \chi_{i 2}, \chi_{i 3}$ and $\chi_{i 4}$ represent the per capita GDP in each year of the investigation period (yuan per capita), population density (person per square kilometer), urbanization level (the ratio of urban population to overall number of people), educational level (represented by illiteracy rate) and fiscal decentralization index. $D_{i j}$ represents the dummy variables that will have an impact on the overall technical efficiency of public cultural expenditures, including the dummy variable of cultural policies, the dummy variable of the eastern, central and western regions and the interactive item of the regional dummy variable and policy variable. Since the evaluation result of overall technical efficiency is a value within the range of 0 to 1 , in order to avoid the biased error brought by OLS estimation and take full advantage of the

${ }^{3}$ The fiscal decentralization index adopted by Qiao (2005) is used for reference. 
cross-sectional and time series data contained in the panel data, the constrained Tobit random-effect panel data model is adopted to make the regression analysis. Relevant data comes from China Statistical Yearbook and Finance Year Book of China of respective years. Using Tobit analysis of Eviews 6.0, we can get the regression results of the five models in Table 4 and Table 5.

\section{Discussion}

It can be seen from Table 4 that the coefficients of eastern and central dummy variables in Model 1, 2, 4 and 5 are negative. For the eastern region, Model 2 and 3 are significant at the $5 \%$ level, while the rest at the $1 \%$ level. For the central region, except for Model 3, which is significant at the $5 \%$ level, the rest models are significant at the $1 \%$ level. This suggests that compared to the western region, the eastern and central regions of our country have relatively low government public cultural expenditure efficiency, which further demonstrates the above analysis results of the overall technical efficiency of public cultural expenditure.

Table 4. The empirical result of influencing factors for local government cultural expenditures I.

\begin{tabular}{|c|c|c|c|c|c|}
\hline Influence Factor & Model 1 & Model 2 & Model 3 & Model 4 & Model 5 \\
\hline $\begin{array}{l}\text { Population } \\
\text { Density }\end{array}$ & $\begin{array}{l}0.00011^{\star * *} \\
(0.289)\end{array}$ & $\begin{array}{l}0.00009^{\star * *} \\
\left(\begin{array}{ll}0 . & 038)\end{array}\right.\end{array}$ & $\begin{array}{l}0.00017^{\star *} \\
(0.000)\end{array}$ & $\begin{array}{l}0.00018^{\star *} \\
(0.0048)\end{array}$ & $\begin{array}{c}0.00013^{* *} \\
(0.049)\end{array}$ \\
\hline Per Capita GDP & $\begin{array}{c}0.0732^{* * *} \\
(0.022)\end{array}$ & $\begin{array}{c}0.0129^{* * *} \\
(0.235)\end{array}$ & $\begin{array}{c}0.0695^{\star * *} \\
(0.043)\end{array}$ & $\begin{array}{l}0.1088^{\star *} \\
(0.256)\end{array}$ & $\begin{array}{c}0.0508^{* *} \\
(0.048)\end{array}$ \\
\hline $\begin{array}{l}\text { Urbanization } \\
\text { Level }\end{array}$ & $\begin{array}{c}0.09089^{*} \\
(0.002)\end{array}$ & $\begin{array}{l}0.0566^{*} \\
(0.0004)\end{array}$ & $\begin{array}{l}0.00778^{* *} \\
(0.000)\end{array}$ & $\begin{array}{l}000783^{\star *} \\
(0.000)\end{array}$ & $\begin{array}{c}0.00226^{\star * *} \\
(0.000)\end{array}$ \\
\hline $\begin{array}{l}\text { Educational } \\
\text { Level }\end{array}$ & $\begin{array}{c}0.00693^{\star * *} \\
(0.0002)\end{array}$ & $\begin{array}{c}0.00733^{\star *} \\
(0.000)\end{array}$ & $\begin{array}{l}0.00964^{* *} \\
(0.0006)\end{array}$ & $\begin{array}{l}0.0113^{\star * *} \\
(0.0011)\end{array}$ & $\begin{array}{l}0.00878^{*} \\
(0.0003)\end{array}$ \\
\hline Fiscal & & $-0.39038^{\star \star}$ & & $-0.41294^{\star * *}$ & $-0.30185^{\star * \star}$ \\
\hline Decentralization & & $(0.012)$ & & $(0.000)$ & $(0.003)$ \\
\hline $\begin{array}{l}\text { Eastern Virtual } \\
\text { Variable (D2) }\end{array}$ & $\begin{array}{c}0.20346^{\star * *} \\
(0.000)\end{array}$ & $\begin{array}{c}-0.31204^{\star *} \\
(0.000)\end{array}$ & & $\begin{array}{c}-0.25353^{\star *} \\
(0.000)\end{array}$ & $\begin{array}{c}0.24167^{\star * *} \\
(0.000)\end{array}$ \\
\hline $\begin{array}{l}\text { Middle Virtual } \\
\text { Variable (D3) }\end{array}$ & $\begin{array}{c}-0.43343^{\star *} \\
(0.000)\end{array}$ & $\begin{array}{c}-0.38278^{\star * *} \\
(0.000)\end{array}$ & & $\begin{array}{c}-0.31978^{\star *} \\
(0.000)\end{array}$ & $\begin{array}{c}-0.35789^{\star *} \\
(0.000)\end{array}$ \\
\hline $\begin{array}{c}\text { Cultural Policy Virtual } \\
\text { Variable (P) }\end{array}$ & & & & $\begin{array}{c}0.100798^{\star * *} \\
(0.002)\end{array}$ & \\
\hline Constant Term & $\begin{array}{c}0.79568^{\star * *} \\
(0.000)\end{array}$ & $\begin{array}{c}1.17555^{\star * *} \\
(0.000)\end{array}$ & $\begin{array}{c}0.81938^{* * *} \\
(0.000)\end{array}$ & $\begin{array}{c}1.67822^{* * *} \\
(0.000)\end{array}$ & $\begin{array}{c}1.29879^{* * *} \\
(0.000)\end{array}$ \\
\hline $\begin{array}{l}\text { Effects of Individual } \\
\text { Standard Deviations }\end{array}$ & $\begin{array}{c}0.33222^{\star * *} \\
(0.000)\end{array}$ & $\begin{array}{c}0.29204^{\star * *} \\
(0.000)\end{array}$ & $\begin{array}{c}0.23207^{\star * *} \\
(0.000)\end{array}$ & $\begin{array}{c}0.26202^{\star * *} \\
(0.000)\end{array}$ & $\begin{array}{c}0.20997^{\star * *} \\
(0.000)\end{array}$ \\
\hline $\begin{array}{l}\text { Interference Item } \\
\text { Standard Deviation }\end{array}$ & $\begin{array}{c}0.079979^{\star * *} \\
(0.000)\end{array}$ & $\begin{array}{c}0.090268^{* * *} \\
(0.000)\end{array}$ & $\begin{array}{c}0.090198^{\star * *} \\
(0.000)\end{array}$ & $\begin{array}{c}0.082377^{\star * *} \\
(0.000)\end{array}$ & $\begin{array}{c}0.087553^{\star * *} \\
(0.000)\end{array}$ \\
\hline $\begin{array}{l}\text { Likelihood-ratio } \\
\text { Test(Chi-square) }\end{array}$ & 368.431 & 299.895 & 291.321 & 292.875 & 302.237 \\
\hline rho & 0.888963 & 0.828765 & 0.851979 & 0.826454 & 0.835112 \\
\hline Log Likelihood & 236.577 & 240.563 & 236.308 & 246.795 & 250.856 \\
\hline
\end{tabular}

Note: “***”, “**” and “*” show the pass the model specification tests at the Significant levels $0.01,0.05$ and 0.1 . 
The result shows that a weak positive correlation exists between the population density and the efficiency of public cultural expenditure, and the significance is relatively obvious, which is consistent with the null hypothesis. Four of the five models show significant positive correlation between the urbanization level and the public cultural expenditure efficiency. Such conclusion suggests that the higher the urbanization level, the stronger the ability of transmission between urban and rural production factors and the higher radioactivity of public culture. The population density and public cultural expenditure efficiency are significantly positively correlated, which verifies the viewpoint of Grossman as well, and scale economy can explain such conclusion.

The fiscal decentralization variable is included into Model 2, and it's found that a negative relation exists between the variable and public cultural expenditure efficiency at the $5 \%$ significance level, while in Model 4 and 5 where the cultural policy variable was contained, the impact of fiscal decentralization on the public cultural expenditure efficiency remains negative and significant at the $1 \%$ level. The significance becomes more obvious, indicating that the result has good robustness. Such result is inconsistent with the mainstream theory of fiscal decentralization in western countries, i.e., a positive correlation exists between fiscal decentralization and government expenditure efficiency. The result can be understood from China's fiscal decentralization system. Unlike the fiscal decentralization in other countries, the fiscal decentralization in China is closely linked with the centralized political system, in such an administrative system, the most important index for local government performance examination is economic growth, and the local government officials have greater incentive to enhance the scale and efficiency of fiscal expenditures with significant shortphase output, while the fiscal cultural expenditure and its efficiency which cannot be easily improved in short term is often ignored. The public expenditures of local government are mostly used in the field of infrastructure, while public cultural expenditures with inconspicuous short-term economic growth contribution are often neglected. Therefore, the execution of this kind of public cultural expenditure budget is slow, and the fund appropriative rate is often low, even there's the situation in which this part of the funds are occupied, which will ultimately affect and reduce the use efficiency of funds, for provinces with higher degree of fiscal decentralization, the local government has stronger ability to control the financial resources, so such effect will possibly be more serious.

In order to further investigate the different influence of fiscal decentralization on the public cultural expenditure efficiency in different regions, the interaction item of fiscal decentralization and dummy variables of the three regions is included into Model 3. The results show (see Table 5) that, the impact of fiscal decentralization on public cultural expenditure efficiency of eastern and central regions is much greater than the western region. Meanwhile, the significance of this effect is $5 \%$ and $1 \%$ respectively for the eastern region and central region, while not obvious for the western region. This is consistent with the previous result of efficiency accounting, which shows that the overall technical efficiency 
Table 5. The empirical result of influencing factors for local government cultural expenditures II.

\begin{tabular}{ccccccc}
\hline Interaction & $\mathrm{D} 1 \times \mathrm{fd}$ & $\mathrm{D} 2 \times \mathrm{fd}$ & $\mathrm{D} 3 \times \mathrm{fd}$ & $\mathrm{D} 1 \times \mathrm{P}$ & $\mathrm{D} 2 \times \mathrm{P}$ & $\mathrm{D} 3 \times \mathrm{P}$ \\
\hline \multirow{2}{*}{ Model 3 } & $-0.39975^{\star *}$ & -0.21557 & $-0.51117^{\star * *}$ & & & \\
& $(0.016)$ & $(0.262)$ & $(0.002)$ & & & \\
Model 5 & & & $0.090254^{\star * *}$ & 0.023033 & $0.054975^{\star *}$ \\
& & & $(0.003)$ & $(0.379)$ & $(0.018)$ \\
\hline
\end{tabular}

Note: “***”, “**” and “*”show the pass the model specification tests at the Significant levels 0.01, 0.05 and 0.1 .

of local public cultural expenditures in China is higher in the western region, while relatively low in the central and east regions. Therefore, moderate fiscal centralization can be carried out to narrow the efficiency variance between the eastern, central and western regions.

It can be seen that, from the log likelihood of the five regression models in the Table 4, the degree of fitting of the model is better than the first three models, which indicates that the cultural policy variable contained in the model is an important factor affecting the efficiency of public cultural expenditure. To examine the influence of cultural policy on the efficiency of public cultural expenditure around 2006, the dummy variable of cultural policy is included into Model 4. The result verifies the null hypothesis, namely, the cultural policies around 2006 significantly improved the efficiency of China's local public cultural expenditure. The interaction item of dummy variable of cultural policy and dummy variable of the three regions is included into Model 5, and it's concluded that cultural policy has a significant promoting effect on the efficiency of public cultural expenditure in the eastern and central regions of China, while positive but not obvious in the western region. Therefore, we can get the following conclusion: the cultural policies around 2006 were conducive to narrowing the differences between the government public cultural expenditure efficiency of the eastern, central and western regions.

\section{Conclusions}

The paper adopts the DEA two-step method to evaluate the three efficiencies of the government public cultural expenditures in 30 provinces of China during 2000 to 2015. The results show that, from the horizontal perspective, there is a significant regional difference in China's public cultural expenditure efficiency, and the efficiency of local public cultural expenditure in the western region is higher than the eastern and central regions, while from the perspective of longitudinal time series, the average overall technical efficiency, pure technical efficiency and scale technical efficiency of the 30 provinces show an increasing trend on the whole. Based on the evaluation results of overall efficiency of public cultural expenditures obtained by accounting, the random effect Tobit regression model is further used to analyze the factors affecting the differences between the public cultural expenditure efficiency of the provincial governments, and the following conclusion which is drawn: per capita GDP, urbanization lev- 
el, population density and educational level all have positive effect on the efficiency of public cultural expenditures. After controlling the economic, social and demographic factors, the effect of fiscal decentralization on the efficiency of public cultural expenditures is negative, and moderate fiscal centralization can be carried out to narrow the efficiency variance between the eastern, central and western regions. Implementation of cultural policies has significant promoting effect on the local government public cultural expenditure efficiency in central and western regions in China, and the current cultural policy can be continuously practiced to reduce the efficiency variances between the government public cultural expenditures of the eastern, central and western regions.

From the perspective of fiscal policy, moderate fiscal centralization in the existing financial system is conductive to improving the efficiency of the government, in addition, for local governments with decreasing returns to scale, the structure of public cultural expenditure should be adjusted and optimized to eliminate the loss of efficiency, while for local governments with increasing returns to scale, the government public cultural input needs to be further increased to improve the efficiency. In order to improve the use efficiency of fiscal funds, the government can transform the original full covered fiscal appropriation mode of public culture into the fiscal appropriation mode depending on public cultural service achievements, for example, the mode of special funds for public cultural services can be used, and the special funds for cultural development, the special funds for development of national film industry and the special funds for development of publishing can be established, improved and promoted. In addition, different financial assistance modes should be adopted for different types of public cultural products. For pure public cultural products and services which the social forces are often unwilling to provide (e.g., the cultural infrastructure construction, collection and protection of cultural heritages, the maintenance of cultural market order, etc.), the government should take complete responsibility for providing them. For quasi-public products or services which the social forces are able but unwilling to provide(e.g., the cultural information engineering, operas going to the countryside, etc.), the government should contribute funds for the purchase of them; for public cultural products and services the social forces are willing and able to provide(e.g., the major festival activities held in communities and rural areas, self-managed cultural organizations, etc.), the government should give appropriate subsidies to them by incentives.

From the perspective of cultural policy, constantly deepening the reform of cultural development strategy and deploying various local cultural resources more reasonably are also important means to improve the efficiency of the government public cultural expenditures. Cultural policy is a generic term for a whole set of institutional regulations, norms, principles and requirements adopted by a country for administrative management in the fields of culture and art, press and publications, radio, film and television, cultural relic and museum, etc.. By adjusting the cultural resources, cultural policy improves the use efficiency of cultural resources, so as to play a dynamic leading role on the culture 
development of a country. Therefore, we should further deepen the reform of cultural administrative system.

\section{Support}

Supported by National Social Science Fund Project (11CGL099).

\section{References}

[1] Han, M. (2009) On the Financial Support for the Construction of Public Cultural Service System Research. Administrative Assets and Finance, 43-45.

[2] He, G.Q. (2009) Adjusting and Perfecting the Guarantee Mechanism of Rural Compulsory Education Funds. China Finance, 22, 39-40.

[3] Wei, P.J. (2005) Cultural Undertakings of the Financial Support. Contemporary Finance, 3, 43-48.

[4] Ma, H.T. and Cheng, L. (2009) Perfecting Fiscal Policy to Promote the Construction of Public Cultural Service System. China Finance, 23, 41-43.

[5] Jiang, G.H. (2011) Public Cultural Services Financial Investment Mechanism. China Administration, 1, 32-36.

[6] Netzer, D. (1992) Differences in Reliance on User Charges by American State and Local Governments. Public Finance Quarterly, 20, 499-511.

https://doi.org/10.1177/109114219202000407

[7] Lin, W.L. (2005) Economic Development Level under the Constraints of Urban and Rural Public Goods Supply: Theoretical Analysis and Its Real Meaning. China Rural Observations, 2, 31-37.

[8] Zhang, N. and Lu, W.C. (2006) Empirical Analysis on the Impact of Rural Labor Force Quality on Agricultural Efficiency in China. Agricultural Technology \& Economy, 2, 74-80.

[9] Grossman, P.J., Mavros, P. and Wassmer, R.W. (1999) Public Sector Technical Inefficiency in Large US Cities. Journal of Urban Economics, 46, 278-299.

[10] Athanassopoulos, A.D. (2003) Strategic Groups, Frontier Benchmarking and Performance Differences: Evidence from the UK Retail Grocery Industry. Journal of Management Studies, 40, 921-953.

http://onlinelibrary.wiley.com/doi/10.1111/1467-6486.00365/full

[11] Milligan, K., Moretti, E. and Oreopoulos, P. (2004) Does Education Improve Citizenship? Evidence from the United States and the United Kingdom. Journal of public Economics, 88, 1667-1695.

[12] Han, H.W. and Miao, Y.Q. (2010) An Empirical Study on the Efficiency of Local Government Health Expenditure. Journal of Finance and Economics, 5, 1-13. 
Submit or recommend next manuscript to SCIRP and we will provide best service for you:

Accepting pre-submission inquiries through Email, Facebook, LinkedIn, Twitter, etc. A wide selection of journals (inclusive of 9 subjects, more than 200 journals)

Providing 24-hour high-quality service

User-friendly online submission system

Fair and swift peer-review system

Efficient typesetting and proofreading procedure

Display of the result of downloads and visits, as well as the number of cited articles Maximum dissemination of your research work

Submit your manuscript at: http://papersubmission.scirp.org/

Or contact jssm@scirp.org 